\title{
HyersUlamRassias stability of some non-linear fractional integral equations using Bielecki metric
}

\author{
R Subashmoorthy ${ }^{1}$ and P. Balasubramaniam ${ }^{2}$ \\ ${ }^{1}$ Amrita Vishwa Vidyapeetham \\ ${ }^{2}$ Universiti of Malaya
}

May 5, 2020

\begin{abstract}
We apply the Bielecki metric on the space $\mathrm{C}([\mathrm{a}, \mathrm{b}])$, to analyze the different types of stabilities of non-linear fractional integral equation corresponding to fractional boundary value problems. Sufficient conditions are obtained to prove stability results for fractional non-linear Volterra and Fredholm integral equations, given by Ulam, Hyer and Rassias. We extend the respective stability results to the fractional integral equations where the domain of integration is an unbounded interval. We provide numerical examples which asserts our stability results.
\end{abstract}

\section{Hosted file}

F_IJDSDE_F.pdf available at https://authorea.com/users/299676/articles/429159hyersulamrassias-stability-of-some-non-linear-fractional-integral-equations-using-

bielecki-metric 